\title{
Phenotypes of Streptococcus mutans isolates in sound and cavitated tooth surfaces and its relationship to early childhood caries in China
}

\section{Shanshan Liu}

the First Affiliated Hospital of Bengbu Medical College

Huihui Li

Bengbu Medical College

Zhenfei Guo

the First Affiliated Hospital of Bengbu Medical College

\section{Yu Sun}

Bengbu Medical College

Qingwei Zheng

Bengbu Medical College

\section{Fuyong $\mathrm{Hu}$}

Bengbu Medical College

Junchang Guan

Bengbu Medical College

Kai Zhang ( $\nabla$ zhangkai29788@163.com )

The First Affiliated Hospital of Bengbu Medical College https://orcid.org/0000-0001-7850-7643

\section{Research article}

Keywords: Streptococcus mutans, early childhood caries, different sites, phenotypes

Posted Date: August 23rd, 2019

DOI: https://doi.org/10.21203/rs.2.13497/v1

License: (1) (1) This work is licensed under a Creative Commons Attribution 4.0 International License. Read Full License 


\section{Abstract}

Background To compare the phenotypes of Streptococcus mutans (S. mutans ) strains isolated from sites with different caries susceptibility of a single subject. Methods This study was carried out in children with early-childhood caries (ECC) and caries-free (CF). The ECC subjects presented two sites: a cavitated lesion (ECC-C) and a sound surface (ECC-F). The CF subjects presented one sound surface. The following phenotypes were evaluated among these three sites: growth pattern, biofilm, exopolysaccharide (EPS), pH drop, and the expression levels of genes (gtfB, gtfC, spaP, sitA, relA, ffh, srn225147, and srn821798). Results All of these phenotypes were detected similarly between ECC-C and ECC-F groups. However, the capacity of biofilm formation, EPS, pH drop and the expression levels of genes (gtfB and spaP) of S. mutans in the CF group were lower compared to those of the ECC group. There was a relatively higher expression of srn821798 compared to that of srn225147 in clinical isolates, and isolates with low expression of srn821798 had lower expression levels of predicted targets (gtfB, gtfC, and spaP). Conclusions These data indicate $S$. mutans isolated from sites with different caries susceptibility of a single subject showed similar characteristics, while the cariogenic potential of the S. mutans isolated from ECC individuals was relatively higher than that of CF subjects.

\section{Background}

Early childhood caries (ECC) is defined as the primary teeth of a child 71 months of age or younger with at least one decayed, missing (due to caries), or filled tooth surface [1]. ECC is one of the most common chronic childhood diseases that aggravates financial burden on the country and exerts negative effects on the family [2, 3]. In the past ten years, the prevalence of ECC has been on the rise, according to the 3rd and 4th National Oral Health Survey. For example, the prevalence of ECC for five-year-old children has increased from $66.0 \%$ to $71.9 \%$ and the mean $\mathrm{dmft}$ (i.e., decayed, missing, filled teeth) has increased from 2.71 to 4.23 [4]. Therefore, preventing and treating ECC in China is important and urgent.

ECC is a chronic infectious disease and Streptococcus mutans (S. mutans) is the major cariogenic bacteria [5]. S. mutans can adhere to tooth surfaces and metabolize carbohydrates, especially sucrose, to produce acid that causes the demineralization of the tooth surface and the onset of caries [6]. Virulencerelated genes of $g t f B, g t f C, s p a P, s r t A$, ffh and relA are involved in the regulation the virulence of $S$. mutans. For example, water-insoluble glucan is an important component of exopolysaccharide (EPS) to enhance the formation of biofilm (EPS). GtfB, encoded by the gtfB gene, synthesizes only water-insoluble glucan. GtfC, encoded by the gtfC gene, produces both water-insoluble and soluble glucan [7]. In addition, sit $A$ and $s p a P$, associated with sucrose-independent adherence, are involved in the utilization of sucrose and enhance cariogenic properties of the biofilm [8]. The mRNAs of $f f h$ and relA have been reported involved in acid tolerance $[9,10]$. Small RNAs (sRNAs) that act by a base-pairing mechanism regulate the expression of target mRNA function in post-transcriptional level [11].

Studies have shown that the cariogenic potential of $S$. mutans isolated from individuals with ECC was higher than that in caries-free children. For example, the synthesis of water-insoluble glucan and the 
capacity of biofilm formation of $S$. mutans isolated from caries-active subjects were greater than those in caries-free children $[12,13]$. However, the virulence phenotypes of $S$. mutans isolated from different microenvironments (i.e., sound enamel and cavitated surfaces) of the same diseased subject remain unknown. Serotype c $(70-80 \%)$ is recognized as the principal strain with the highest detection rate in the oral cavity. Thus, in this study, phenotypes and expression of virulence-related genes in S. mutans isolated from tooth surfaces with different caries susceptibility with c serotype between ECC and cariesfree children were assessed.

\section{Methods}

\section{Collection of dental plaque and recording of severity of ECC}

The mean scores of the $\mathrm{dmft}$ index (i.e., the decayed, missing, filled-teeth index) and dmfs index (i.e., the decayed, missing, filled-tooth-surfaces index) were used to evaluate the severity of ECC [14]. Dentalplaque samples were collected with sterile cotton sticks from the tooth surfaces of ECC and non-ECC children aged three to five years old. The ECC subjects presented two donor sites: caries-active sites (ECCC) and sound sites (ECC-F), whereas the caries-free subjects presented only sound sites (CF). The cotton sticks were placed in a sterile centrifuge tube with $0.9 \%$ saline and were taken to the laboratory on ice for $4 \mathrm{~h}$.

\section{Isolation of clinical $S$. mutans isolates}

The centrifuge tube with the plaque sample was mixed for $30 \mathrm{sec}$ and $50 \mathrm{ul}$ of saline was plated on Trypticase Yeast-Extract Cysteine Sucrose Bacitracin (TYCSB) agar. Three colonies were selected randomly from each dental-plaque sample according to the morphology of S. mutans UA159 (ATCC 700610) after culturing for 48 hours at $37^{\circ} \mathrm{C}$ under $5 \% \mathrm{CO}_{2}$. Clinical S. mutans were confirmed according to their reaction to mannitol, sorbitol, raffinose, melibiose, aesculin, and hydrolyse arginine [15].

\section{Identification of c serotypes}

All of the isolates were cultured overnight and DNA was extracted from clinical S. mutans isolates by Bacterial Genome DNA Extracton Kit (Tiangen Biotech, Beijing, China) according to the manufacturer's instructions. The confirmation of the $c$ serotype was carried out by polymerase chain reaction (PCR) using serotype-specific primers [16]. The reaction condition of PCR for c serotype included the following: denaturation at $96^{\circ} \mathrm{C}$ for $2 \mathrm{~min} ; 25$ cycles consisting of $15 \mathrm{~s}$ of denaturation at $96^{\circ} \mathrm{C} ; 30 \mathrm{~s}$ of annealing at $61^{\circ} \mathrm{C}$; and $1 \mathrm{~min}$ of extension at $72^{\circ} \mathrm{C}$. The amplification products were then observed through electrophoresis in agarose gels. S. mutans UA159 was used as a positive reference.

\section{Growth monitoring and $\mathrm{pH}$ changes at the early stationary phase}

All of the $S$. mutans clinical isolates $(n=28)$ with the c serotype from caries-free children were selected to form the caries-free group (CF). Selected ECC individuals contained at least one $S$. mutans isolated from 
both caries-active and caries-free tooth surfaces at the same time in order to reduce error. S. mutans clinical isolates with the $c$ serotype from caries-active and caries-free tooth surfaces from 10 children with the top-10 dmfs scores were selected to form the caries-active group (ECC-C; $n=23$ ) and caries-free group (ECC-F; $n=23$ ) of children with ECC. Each of the clinical $S$. mutans isolates was incubated in brain heart infusion (BHI) broth and growth was monitored at the optical density (OD) of $600 \mathrm{~nm}$ every $6 \mathrm{~h}$. The $\mathrm{pH}$ value at $12 \mathrm{~h}$, which represents the early stationary phase, was tested using a $\mathrm{pH}$ meter.

\section{Biofilm formation and final $\mathrm{pH}$ detection}

The biofilm assay was performed according to Zhou et al., (2018) with a minor adjustment [41]. Twohundred $\mu \mathrm{L}$ of $\mathrm{BHI}$ broth of each isolate with $1 \times 10^{7} \mathrm{CFU} / \mathrm{mL}$ S. mutans and $1 \%$ sucrose were added in 96-well plates. After culturing at $37^{\circ} \mathrm{C}$ under $5 \% \mathrm{CO}_{2}$ for $24 \mathrm{~h}$, the supernatant was removed for $\mathrm{pH}$ assessment and $100 \mu \mathrm{L}$ of $0.05 \%$ crystal violet (CV) was added to the well for staining for $15 \mathrm{~min}$. Then, the stained biofilm was washed twice with $0.9 \%$ saline and was de-stained with $100 \%$ ethanol. Lastly, 100 $\mu \mathrm{L}$ of each sample was transferred to a new 96-well plate and was quantified at $570 \mathrm{~nm}$.

\section{Production of EPS}

The production of EPS was evaluated by the congo red (CR)-binding assay $[17,18]$. Fifty $\mu \mathrm{L}$ of $\mathrm{CR}$ along with $100 \mu \mathrm{L}$ of fresh BHI broth was added to each well that was cultured with 24-h biofilm, as well as to a blank well (blank CR). The incubation medium was then transferred to $200-\mu \mathrm{L}$ microcentrifuge tubes and centrifuged at $10,000 \mathrm{~g}$ for $5 \mathrm{~min}$ after incubating for $2 \mathrm{~h}$. The supernatants were transferred to empty wells in a microtiter plate and were detected at $490 \mathrm{~nm}$ as follows: OD bound CR (EPS production) $=$ OD blank-OD supernatant.

\section{Quantitative real-time PCR}

In each group, 10 isolates were selected randomly for mRNA detection. $S$. mutans biofilms were grown on 6-well plates at $37^{\circ} \mathrm{C}$ under $5 \% \mathrm{CO}_{2}$ for $24 \mathrm{~h}$. The supernatant was removed and the biofilm was rinsed twice with sterilized saline to dislodge nonadherent bacteria. The total RNA was extracted and purified using the miRNeasy Mini Kit (Qiagen, German), and was then subjected to reverse-transcription PCR. For mRNAs ( $g t f B, g t f C, s p a P$, sttA, ffh, and relA), the PrimeScript ${ }^{\text {TM }}$ RT reagent Kit with gDNA Eraser (Takara, Japan) was used for reverse-transcription PCR and real-time quantitative-PCR (RT-qPCR) was performed with TB Green ${ }^{\text {TM }}$ Premix Ex Taq ${ }^{\text {TM }}$ II (Takara, Japan). Specifically, the mRNAs of gtfB, spaP, sitA, ffh and relA were potential targets for srn225147, and the mRNAs of $g t f B$, gtfC, spaP, sitA, and ffh were predicted targets for $s r n 821798$ according to target prediction by IntaRNA (http://rna.informatik.unifreiburg.de/IntaRNA/Input.jsp) and RNAPredator (http://nibiru.tbi.univie.ac.at/RNApredator/introduction.html) [19-21]. For sRNAs (srn225147 and srn821798), Mir- $\mathrm{X}^{\mathrm{TM}}$ miRNA First Strand Synthesis Kit (Takara, Japan) was used for reverse-transcription PCR, and RT-qPCR was performed with Mir- $\mathrm{X}^{\mathrm{TM}}$ miRNA qRT-PCR TB Green ${ }^{\mathrm{TM}}$ Kit (Takara, Japan). The PCR reaction conditions for mRNAs included the following: denaturation at $95^{\circ} \mathrm{C}$ for $30 \mathrm{~s} ; 40$ cycles consisting of $5 \mathrm{~s}$ of denaturation at $95^{\circ} \mathrm{C}$; and $30 \mathrm{~s}$ of annealing at $55^{\circ} \mathrm{C}$. The PCR reaction conditions for srn 225147 
were as follows: denaturation at $95^{\circ} \mathrm{C}$ for $10 \mathrm{~s} ; 40$ cycles consisting of $5 \mathrm{~s}$ of denaturation at $95^{\circ} \mathrm{C}$; and 20 $\mathrm{s}$ of annealing at $55^{\circ} \mathrm{C}$. The PCR reaction conditions for srn821798 were as follows: denaturation at $95^{\circ} \mathrm{C}$ for $10 \mathrm{~s} ; 40$ cycles consisting of $5 \mathrm{~s}$ of denaturation at $95^{\circ} \mathrm{C}$; and $20 \mathrm{~s}$ of annealing at $50^{\circ} \mathrm{C}$. The primers for $16 S$ rRNA, gtfB, gtfC, spaP, sitA, ffh, and relA were synthesized according to previous studies [8, 2224].

The primer sequences are listed in Table 1.

\section{Statistical analysis}

IBM SPSS 20.0 software (IBM, Armonk, NY, USA) was used to analyze the data. Chi-square tests were used for qualitative data. One-way analyses of variance (ANOVAs) followed by Tukey's HSD tests or Kruskal-Wallis tests were used for quantitative data. Spearman-rank correlation coefficients were used to evaluate correlations. A $p$ value less than 0.05 was considered statistically significant.

\section{Results}

\section{The characteristics of isolates under planktonic status}

There were 137 S. mutans clinical strains with c serotype isolated from 31 children with both ECC-C and ECC-F sites, and a total of $28 \mathrm{~S}$. mutans clinical strains were isolated from $16 \mathrm{CF}$ children. For this part of the study, all of the $S$. mutans clinical isolates $(n=28)$ with the c serotype from 16 caries-free children were selected to form the CF group. S. mutans clinical isolates with the c serotype from 10 children with the top-10 dmfs scores were selected to form the ECC-C group $(n=23)$ and ECC-F group $(n=23)$. Virulence characteristics including growth patterning, biofilm formation, $\mathrm{pH}$ changes, and EPS formation were evaluated among the three groups. A similar growth pattern of $S$. mutans isolated from the three groups (ECC-C, ECC-F, and CF) was found under planktonic status (Fig. 1a). All of the isolates reached the early stationary phase at $12 \mathrm{~h}$. There was no statistical difference in the $\mathrm{pH}$ value at $12 \mathrm{~h}$ among these three groups ( $p=0.066$; Fig. 1b).

\section{The characteristics of isolates under biofilm status}

No significant difference in the capacity of biofilm formation was observed between the ECC-C and ECC-F groups ( $p=0.947$ ), while the capacity of biofilm formation was higher in both the ECC-C and ECC-F groups compared to that in the CF group ( $p=0.018$ for ECC-C versus CF; $p=0.043$ for ECC-F versus CF; Fig. 2a). There was no difference in the $\mathrm{pH}$ value between the ECC-C and ECC-F groups $(p=0.928)$. However, the $\mathrm{pH}$ value was lower in both the ECC-C and ECC-F groups compared to that in the CF group ( $p$ $=0.017$ for ECC-C versus CF; $p=0.046$ for ECC-F versus CF; Fig. $2 b$ ). The production of EPS in both ECC-C and ECC-F groups were higher than that in the CF group ( $p<0.001$ for ECC-C versus CF; $p=0.006$ for ECC$F$ versus $C F$ ), and that of the ECC-C group was higher than it in the ECC-F group ( $p=0.048$; Fig. $2 c)$.

\section{The relative expression of mRNAs and sRNAs under biofilm status}


The expression level of $g t f B$ of one isolate in the ECC-C group was defined as an expression level equal to 1.0. The relative expression levels of four genes ( $g t f B, g t f C$, spaP, and $s t t A)$ were associated with the production of EPS and the levels of two genes ( $f f h$ and $r e / A$ ) were related to acid production. The expression levels of these six genes were evaluated in this study. The relative expression levels of $g t f B$ and $s p a P$ in the ECC-C group were higher than those in the CF group $(p=0.040$ for $g t f B ; p=0.011$ for $s p a P)$, and both genes were positively correlated to the production of EPS $(r=0.700$ and $p<0.001$ for spaP; $r=0.638$ and $p<0.001$ for $g t f B ;$ Fig 3 ). No significant difference was found in the expression levels of $g t f C$, sitA, ffh and relA among the three groups ( $p=0.077$ for $g t f C, p=0.155$ for $\operatorname{sit} A, p=0.077$ for $f f h$, and $p=0.971$ for relA). Next, the mRNAs of gtfB, spaP, sitA, ffh, and relA were potential targets for srn225147, and the mRNAs of gtfB, gtfC, spaP, sitA, and ffh were predicted targets for srn821798, according to target prediction by IntaRNA and RNAPredator. The relative expression level of srn225147 in the ECC-C group was higher than that in the CF group ( $p=0.009$ for ECC-C versus CF; $p=0.018$ for ECC-F versus CF; Fig. 4a). No significant difference was found in the expression of srn821798 among the three groups (Fig. 4c). However, the expression level of srn821798 was higher than srn225147 in the 30 isolates $(p=0.002)$. In addition, the expression levels of $g t f B, g t f C$, and spaP in isolates with low expression of $\operatorname{srn} 821798(\mathrm{n}=$ end 10$)$ were lower than those in isolates with high expression of $\operatorname{srn} 821798(\mathrm{n}=$ top 10; $p=0.039$ for $g t f B ; p=0.016$ for $g t f C, p=0.022$ for $s p a P$; Fig. $4 \mathrm{~d}$ ), while, no significant difference was found for srn225147 (Fig. 4b).

\section{Discussion}

Studies has shown that the microbial flora in tooth surfaces with different caries susceptibility or saliva from caries-active and caries-free children or adults are different from one another [12, 25-27]. There are more than 700 bacterial species colonized in the oral cavity. Among them, S. mutans is identified as the most important pathogenic bacteria for dental caries [28, 29]. Recent studies suggest that the virulence of $S$. mutans isolated from caries-active subjects is high in comparison to that in caries-free subjects [12, 13]. However, the characteristics of $S$. mutans isolated between the caries-active and sound tooth surfaces from a single individual, as well as from the sound tooth surfaces between ECC and non-ECC individuals, have remained unknown. Thus, exploration of these characteristics may play important roles for future clinical practice.

Only ECC children that had the $S$. mutans isolated from the caries-active and sound tooth surfaces were included in order to exclude other factors, such as different dietary habits or oral-hygiene behaviors that may affect the occurrence of dental caries [30,31]. Moreover, the $S$. mutans were isolated from children living in the same district. The growth pattern of $S$. mutans isolates under the planktonic status were similar, and similar models were found on phenotypes of $S$. mutans under the biofilm status between the groups of ECC-C and ECC-F. These results remind us that the prevention of dental caries is important for every tooth because the virulence of $S$. mutans colonized in dental plaque of a single subject is similar, such that it could disperse and colonize at other tooth surfaces. Conversely, virulent phenotypes were high in the ECC-F or ECC-C groups compared to that in the CF group. This result is consistent with a previous report, in spite of different details of the study [32]. In that study, the bacterial activity (e.g. 
lactobacilli) evaluated in the ECC-C group was higher than it in ECC-F group, and a saccharolytic fusobacteria was most active in the CF group and was less active in the ECC-C and ECC-F groups. These results suggest that $S$. mutans colonized in the tooth surface of individuals with caries might have the same cariogenic potential, while the cariogenic potential of the $S$. mutans colonized in the tooth surface of sound individual is relatively lower.

Genes of $g t f B$, gtfC, spaP, and $s i t A$ have been reported to be virulent factors involved in the regulation of EPS synthesis and biofilm formation in $S$. mutans $[33,34]$. The relative expression levels of $g t f B$ and $s p a P$ in the ECC-C group were higher than those in the CF group, and they were positively correlated to the production of EPS. These results are in accordance with previous studies that have shown that the virulence gene gtfB contributes to the adherence, synthesis of EPS and to biofilm formation under a sucrose environment, and that $s p a P$ is also involved in such adherence [35, 36]. Importantly, sRNAs coordinate adaptation processes in response to environmental changes in bacteria by regulating target mRNA expression [37-41]. Specifically, srn225147 and srn821798 were sequenced in our previous studies $[22,23]$. Virulence-related genes selected in our present study were predicted targets for these two sRNAs according to IntaRNA and RNAPredator. Therefore, the relative expression of these two sRNAs were tested. The expression level of $s r n 821798$ was higher than that of $s r n 225147$ in the 30 isolates, and the expression levels of $\mathrm{gtfB}, \mathrm{gtfC}$, and $\mathrm{spaP}$ in isolates with low expression of $\mathrm{srn} 821798$ were lower than those in isolates with high expression of $s r n 821798$. Thus, we speculate that srn821798 may be import in maintaining homeostasis and adherence of $S$. mutans.

Although this study provided practical information, there are some limitations. Only the $S$. mutans isolated from children with high dmfs scores were selected to compose the ECC-C and ECC-F groups. The phenotypes of $S$. mutans between the groups of ECC-C and ECC-F weren similar, but whether $S$. mutans isolated from different sites of a single subject are closely related isolates is still unknown. Multilocus sequence typing of these isolates will be needed in the future.

\section{Conclusions}

In conclusion, S. mutans isolated from sites with different caries susceptibility of a single subject showed similar phenotypes. However, the cariogenic potential of the $S$. mutans isolated from ECC individuals was relatively higher than that of CF subjects. These findings may improve our knowledge on $S$. mutans virulence and the consequent development of dental caries.

\section{Abbreviations}

S. mutans: Streptococcus mutans, ECC: early-childhood caries; CF caries-free; ECC-C: a cavitated lesion from children with early-childhood caries; ECC-F: a sound surface from children with early-childhood caries; EPS: exopolysaccharide; dmft: decayed, missing, filled teeth; TYCSB: Trypticase Yeast-Extract Cysteine Sucrose Bacitracin; PCR: polymerase chain reaction; BHI: brain heart infusion; CV: crystal violet; 
CR: congo red; RT-qPCR: real-time quantitative-PCR; sRNAs: Small RNAs; ANOVAs: One-way analyses of variance; dmfs: the decayed, missing, filled-tooth-surfaces.

\section{Declarations}

This study was approved by the Ethics Committee of [2017] KY011 of the First Affiliated Hospital of Bengbu Medical College. Informed consent for participation under 16 years old in the study was obtained from their parent or guardian.

\section{Consent to publish}

Not applicable.

\section{Availability of data and materials}

The data and materials of the present study were available from the corresponding author.

\section{Competing interests}

The authors declare that they have no conflict of interest.

\section{Funding}

This study was funded by the Natural Science Fund of Education Department of Anhui province [grant number KJ2018A0223], the Key Research and Development Projects of Department of Science and Technology of Anhui Province [grant number 1804h08020290], and the Foundation for Innovative Research Groups of Anhui province [2016-40].

\section{Authors' contributions}

KZ and SL conceived and designed the experiments; SL, HL, and ZG conducted the experiments; YS, QZ, and FH analyzed the data; SSL wrote the manuscript; KZ and JG revised the manuscript. All authors read and approved the manuscript.

\section{Acknowledgements}

Not applicable.

\section{References}

[1] Bartosova M. Svetlak M. Kukletova M. Borilova Linhartova P. Dusek L. Izakovicova Holla L. Emotional stimuli candidates for behavioural intervention in the prevention of early childhood caries: a pilot study. BMC Oral Health. 2019; 19: 33. 
[2] Correa-Faria P, Daher A, Freire M, de Abreu M, Bonecker M, Costa LR. Impact of untreated dental caries severity on the quality of life of preschool children and their families: a cross-sectional study. Qual Life Res. 2018; 27: 3191-3198.

[3] Wuollet E, Laisi S, Alaluusua S, Waltimo-Siren J. The association between molar-incisor hypomineralization and dental caries with socioeconomic status as an explanatory variable in a group of Finnish children. Int J Environ Res Public Health. 2018; 15. pii: E1324.

[4] Du MQ, Li Z, Jiang H, Wang X, Feng XP, Hu Y, Lin HC, Wang B, Si Y, Wang CX, Zheng SG, Liu XN, Rong WS, Wang WJ, Tai BJ. Dental caries status and its associated factors among 3- to 5-year-old children in China: a national survey. Chin J Dent Res. 2018; 21: 167-179.

[5] Jiang S, Chen S, Zhang C, Zhao X, Huang X, Cai Z. Effect of the biofilm age and starvation on acid tolerance of biofilm formed by Streptococcus mutans isolated from caries-active and caries-free adults. Int J Mol Sci. 2017; 18. pii: E713.

[6] Matsui R, Cvitkovitch D. Acid tolerance mechanisms utilized by Streptococcus mutans. Future Microbiol. 2010; 5: 403-417.

[7] Thurnheer T, van der Ploeg JR, Giertsen E, Guggenheim B. Effects of Streptococcus mutans gtfC deficiency on mixed oral biofilms in vitro. Caries Res. 2006; 40: 163-171.

[8] Zhou Y, Millhouse E, Shaw T, Lappin DF, Rajendran R, Bagg J, Lin H, Ramage G. Evaluating Streptococcus mutans strain dependent characteristics in a polymicrobial biofilm community. Front Microbiol. 2018; 9: 1498.

[9] Crowley PJ, Svensater G, Snoep JL, Bleiweis AS, Brady LJ. An ffh mutant of Streptococcus mutans is viable and able to physiologically adapt to low pH in continuous culture. FEMS Microbiol Lett. 2004; 234: 315-324.

[10] Lemos JA, Brown TA, Jr., Burne RA (2004) Effects of relA on key virulence properties of planktonic and biofilm populations of Streptococcus mutans. Infect Immun 72 (3): 1431-1440. https://doi.org/10.1128/iai.72.3.1431-1440.2004.

[11] Brantl, S. Bacterial chromosome-encoded small regulatory RNAs. Future Microbiology. 2009; 4: 85103.

[12] Jiang S, Gao X, Jin L, Lo EC. Salivary microbiome diversity in caries-free and caries-affected children. Int J Mol Sci. 2016; 17. pii: E1978.

[13] Zhao W, Li W, Lin J, Chen Z, Yu D. Effect of sucrose concentration on sucrose-dependent adhesion and glucosyltransferase expression of $S$. mutans in children with severe early-childhood caries (S-ECC). Nutrients. 2014; 6: 3572-3586. 
[14] Nobile CG, Fortunato L, Bianco A, Pileggi C, Pavia M. Pattern and severity of early childhood caries in Southern Italy: a preschool-based cross-sectional study. BMC Public Health. 2014; 14: 206.

[15] Yu LX, Tao Y, Qiu RM, Zhou Y, Zhi QH, Lin HC. Genetic polymorphisms of the sortase A gene and social-behavioural factors associated with caries in children: a case-control study. BMC Oral Health. 2015; 15: 54.

[16] Shibata Y, Ozaki K, Seki M, Kawato T, Tanaka H, Nakano Y, Yamashita Y. Analysis of loci required for determination of serotype antigenicity in Streptococcus mutans and its clinical utilization. J Clin Microbiol. 2003; 41: 4107-4112.

[17] Kulshrestha S, Khan S, Hasan S, Khan ME, Misba L, Khan AU. Calcium fluoride nanoparticles induced suppression of Streptococcus mutans biofilm: an in vitro and in vivo approach. Appl Microbiol Biotechnol. 2016; 100: 1901-1914.

[18] Misba L, Khan AU. Enhanced photodynamic therapy using light fractionation against Streptococcus mutans biofilm: type I and type II mechanism. Future Microbiol. 2018; 13: 437-454.

[19] Busch A, Richter AS, Backofen R. IntaRNA: efficient prediction of bacterial sRNA targets incorporating target site accessibility and seed regions. Bioinformatics. 2008; 24: 2849-2856.

[20] Eggenhofer F, Tafer H, Stadler PF, Hofacker IL. RNApredator: fast accessibility-based prediction of sRNA targets. Nucleic Acids Res. 2011; 39: W149-154.

[21] Mann M, Wright PR, Backofen R. IntaRNA 2.0: enhanced and customizable prediction of RNA-RNA interactions. Nucleic Acids Res. 2017; 45: W435-439.

[22] Liu S, Tao Y, Yu L, Zhuang P, Zhi Q, Zhou Y, Lin H. Analysis of Small RNAs in Streptococcus mutans under Acid Stress-A New Insight for Caries Research. Int J Mol Sci. 2016; 17. pii: E1529.

[23] Liu SS, Zhu WH, Zhi QH, Liu J, Wang Y, Lin HC. Analysis of sucrose-induced small RNAs in Streptococcus mutans in the presence of different sucrose concentrations. Appl Microbiol Biotechnol. 2017; 101: 5739-5748.

[24] Singh K, Senadheera DB, Levesque CM, Cvitkovitch DG. The copYAZ Operon Functions in Copper Efflux, Biofilm Formation, Genetic Transformation, and Stress Tolerance in Streptococcus mutans. J Bacteriol. 2015; 197: 2545-2557.

[25] He J, Tu Q, Ge Y, Qin Y, Cui B, Hu X, Wang Y, Deng Y, Wang K, Van Nostrand JD, Li J, Zhou J, Li Y, Zhou $X$. Taxonomic and functional analyses of the supragingival microbiome from caries-affected and cariesfree hosts. Microb Ecol. 2018; 75: 543-554.

[26] Xiao J, Grier A, Faustoferri RC, Alzoubi S, Gill AL, Feng C, Liu Y, Quivey RG, Kopycka-Kedzierawski DT, Koo H, Gill SR. Association between oral Candida and bacteriome in children with severe ECC. J Dent Res. 
[27] Richards VP, Alvarez AJ, Luce AR, Bedenbaugh M, Mitchell ML, Burne RA, Nascimento MM. Microbiomes of site-specific dental plaques from children with different caries status. Infect Immun. 2017; 85: e00106-17.

[28] Saraithong P, Pattanaporn K, Chen Z, Khongkhunthian S, Laohapensang P, Chhun N, Pattanaporn W, Gaw HY, Li Y. Streptococcus mutans and Streptococcus sobrinus colonization and caries experience in 3and 5-year-old Thai children. Clin Oral Invest. 2015; 19: 1955.

[29] Garcia SS, Blackledge MS, Michalek S, Su L, Ptacek T, Eipers P, Morrow C, Lefkowitz EJ, Melander C, Wu H. Targeting of Streptococcus mutans biofilms by a novel small molecule prevents dental caries and preserves the oral microbiome. J Dent Res. 2017; 96: 807-814.

[30] Marchesan JT, Morelli T, Moss K, Preisser JS, Zandona AF, Offenbacher S, Beck J. Interdental cleaning is associated with decreased oral disease prevalence. J Dent Res. 2018; 97: 773-778.

[31] Vega-Lopez S, Lindberg NM, Eckert GJ, Nicholson EL, Maupome G. Association of added sugar intake and caries-related experiences among individuals of Mexican origin. Community Dent Oral Epidemiol. 2018; 46: 376-384.

[32] Henne K, Gunesch AP, Walther C, Meyer-Lueckel H, Conrads G, Esteves-Oliveira M. Analysis of bacterial activity in sound and cariogenic biofilm: a pilot in vivo Study. Caries Res. 2016; 50: 480-488.

[33] Castillo Pedraza MC, Novais TF, Faustoferri RC, Quivey RG, Jr., Terekhov A, Hamaker BR, Klein MI. Extracellular DNA and lipoteichoic acids interact with exopolysaccharides in the extracellular matrix of Streptococcus mutans biofilms. Biofouling. 2017; 33: 722-740.

[34] Yang Y, Mao M, Lei L, Li M, Yin J, Ma X, Tao X, Yang Y, Hu T. Regulation of water-soluble glucan synthesis by the Streptococcus mutans dexA gene effects biofilm aggregation and cariogenic pathogenicity. Mol Oral Microbiol. 2019; 34: 51-63.

[35] Chen L, Ren Z, Zhou X, Zeng J, Zou J, Li Y. Inhibition of Streptococcus mutans biofilm formation, extracellular polysaccharide production, and virulence by an oxazole derivative. Appl Microbiol Biotechnol. 2016; 100: 857-867.

[36] Heim KP, Sullan RM, Crowley PJ, El-Kirat-Chatel S, Beaussart A, Tang W, Besingi R, Dufrene YF, Brady LJ. Identification of a supramolecular functional architecture of Streptococcus mutans adhesin P1 on the bacterial cell surface. J Biol Chem. 2015; 290: 9002-9019.

[37] Choi JW, Kim SC, Hong SH, Lee HJ. Secretable small RNAs via outer membrane vesicles in periodontal pathogens. J Dent Res. 2017; 96: 458-466. 
[38] Choi JW, Kwon TY, Hong SH, Lee HJ. Isolation and characterization of a microRNA-size secretable small RNA in Streptococcus sanguinis. Cell Biochem Biophys. 2016; 76: 293-301.

[39] Kang SM, Choi JW, Lee Y, Hong SH, Lee HJ. Identification of microRNA-size, small RNAs in Escherichia coli. Curr Microbiol. 2013; 67: 609-613.

[40] Lee HJ, Hong SH. Analysis of microRNA-size, small RNAs in Streptococcus mutans by deep sequencing. FEMS Microbiol Lett. 2012; 326: 131-136.

[41] Schoenfelder SMK, Lange C, Prakash SA, Marincola G, Lerch MF, Wencker FDR, Forstner KU, Sharma $\mathrm{CM}$, Ziebuhr W. The small non-coding RNA RsaE influences extracellular matrix composition in Staphylococcus epidermidis biofilm communities. PLoS Pathog. 2019; 15: e1007618.

\section{Tables}

Table 1 Primer sequences

\begin{tabular}{|c|c|}
\hline ID & Primer sequences \\
\hline c serotype $(F)$ & CGG AGT GCT TTT TAC AAG TGC TGG \\
\hline c serotype (R) & AAC CAC GGC CAG CAA ACC CTT TAT \\
\hline$g t f B(F)$ & GATCAAGATGTTCGCGTTGC \\
\hline$g t f B(\mathrm{R})$ & ACACATACTGCGGTGCCATT \\
\hline$g t f C(\mathrm{~F})$ & GATCAAGAAGCGGCTGGTTT \\
\hline$g t f C(\mathrm{R})$ & ACATGACGCGTGAATCAAGG \\
\hline $\operatorname{spaP}(\mathrm{F})$ & TCCGCTTATACAGGTCAAGTTG \\
\hline $\operatorname{spaP}(\mathrm{R})$ & GAGAAGCTACTGATAGAAGGGC \\
\hline $\operatorname{srt} A(\mathrm{~F})$ & GAAGCTTCCTGTAATTGGCG \\
\hline $\operatorname{srt} A(\mathrm{R})$ & TTCATCGTTCCAGCACCATA \\
\hline$f f h(F)$ & AAGGTAAGCAAGTCTCCCATTC \\
\hline ffh $(\mathrm{R})$ & TCCGTCAAATCACTGGAAAAC \\
\hline $\operatorname{relA}(\mathrm{F})$ & ACAAAAAGGGTATCGTCCGTACAT \\
\hline $\operatorname{relA}(\mathrm{R})$ & AATCACGCTTGGTATTGCTAATTG \\
\hline $\operatorname{srn} 225147$ & ATTGACTTTGAGTCTGTGC \\
\hline $\operatorname{srn} 821798$ & GATTAGTTATCAGATTTT \\
\hline $16 S$ rRNA (F) & CTTACCAGGTCTTGACATCCCG \\
\hline $16 S$ rRNA (R) & ACCCAACATCTCACGACACGAG \\
\hline
\end{tabular}

\section{Figures}


a

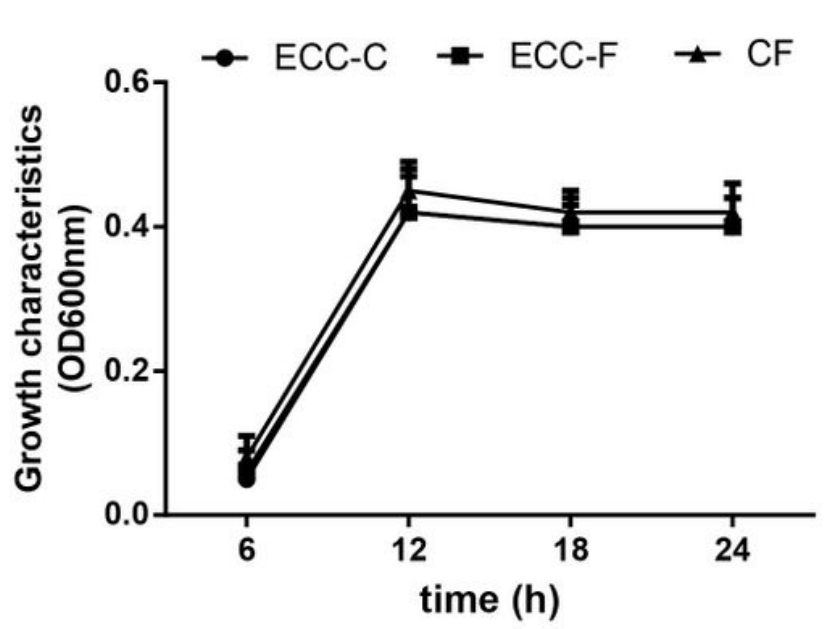

b

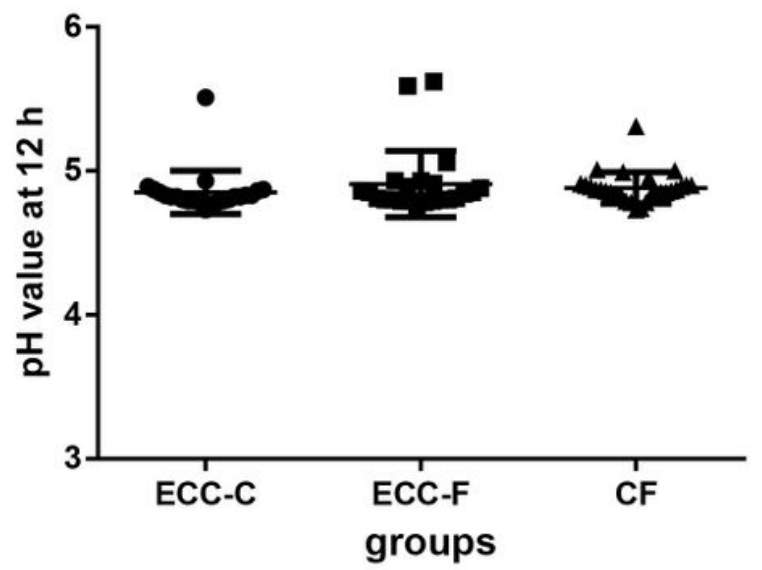

Figure 1

Growth curve and $\mathrm{pH}$ value of $\mathrm{S}$. mutans under planktonic status

a



b

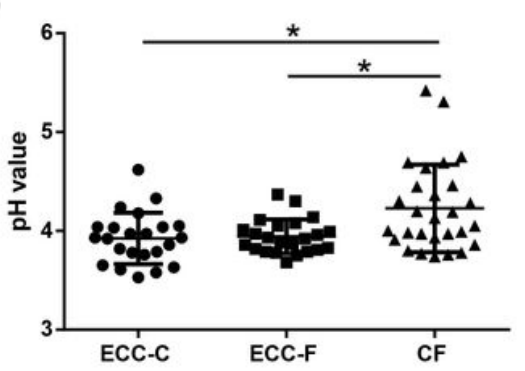

C

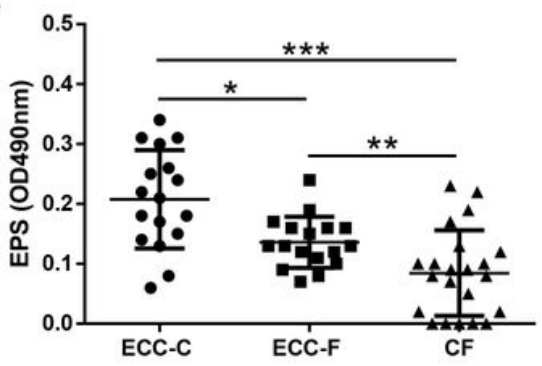

Figure 2

The virulent characteristics of isolates under biofilm status. (a) The biomass of the $24 \mathrm{~h}$ biofilm; (b) The final $\mathrm{pH}$ value of the $24 \mathrm{~h}$ biofilm; (c) The production of EPS of the $24 \mathrm{~h}$ biofilm. * represents $\mathrm{p}$ value < 0.05 , ** represents $p$ value $<0.01$, and ${ }^{* \star *}$ represents $p$ value $<0.001$. 
a

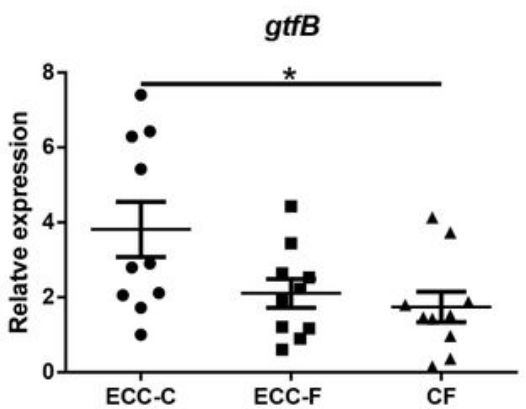

C



e

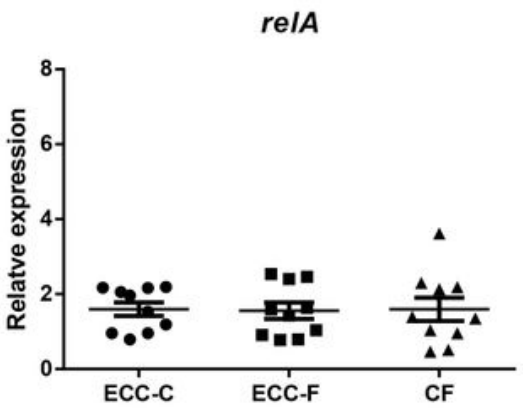

g

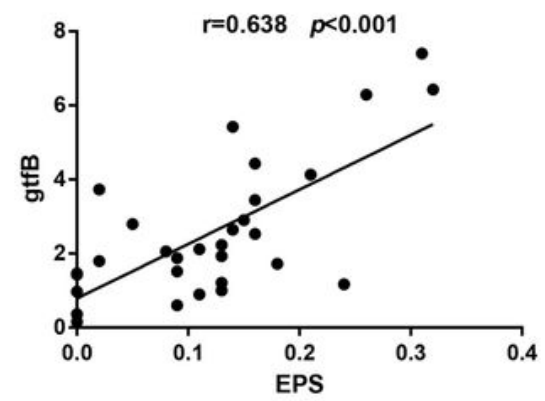

b

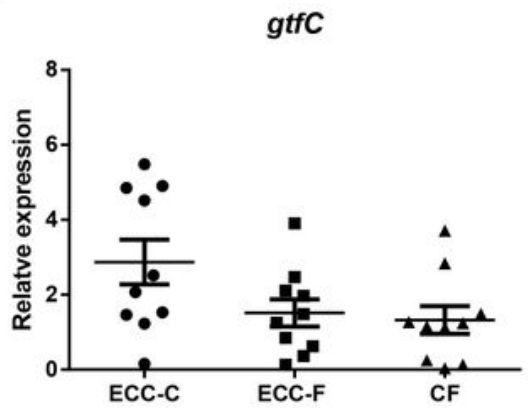

d



f

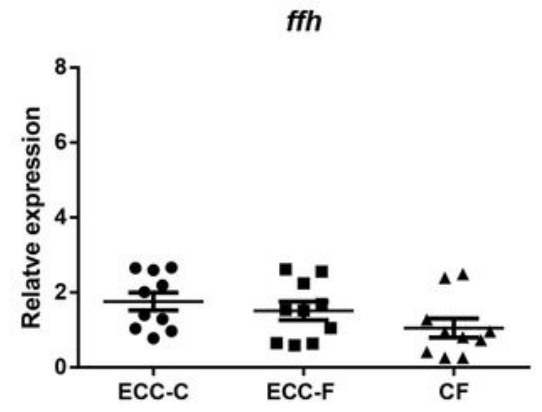

h

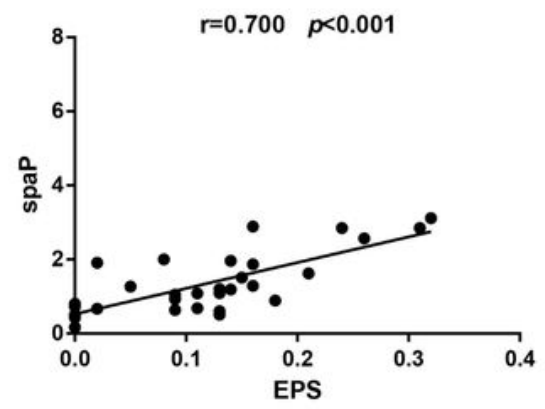

Figure 3

The relative expression levels of virulent genes and correlation between virulent genes and phenotypes. (a-f) The relative expression levels of reported virulent genes of gtfB, gtfC, spaP, srtA, relA, and ffh. The expression level of gtfB of one isolate in the ECC-C group was defined as 1.0. * represents $p$ value $<0.05$; ( $g$-h) The correlation between virulent genes (gtfB and spaP) and EPS. 
a

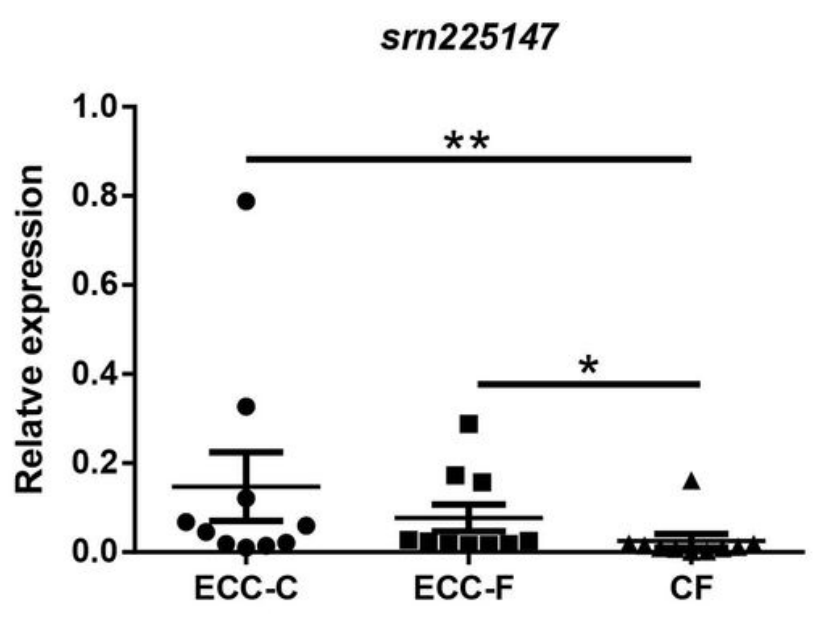

C



b

srn225147



d

srn821798

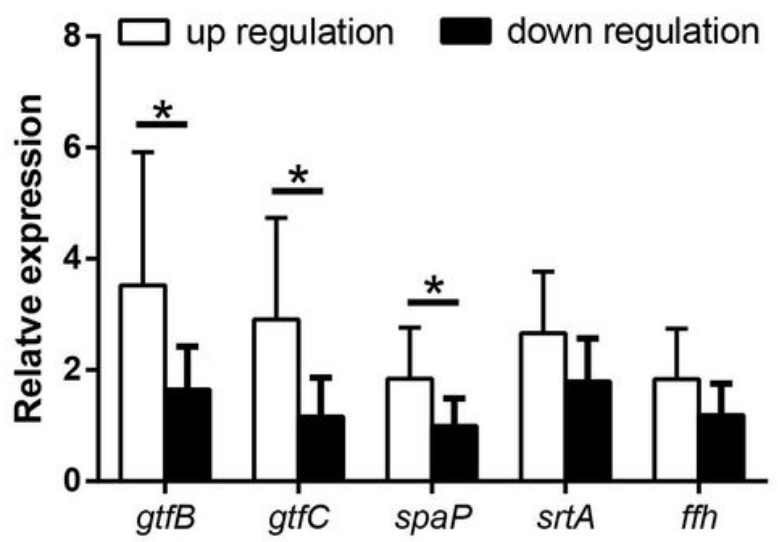

Figure 4

The relative expression levels of sRNAs and their associations with predicted targets. The mRNAs of gtfB, spaP, sitA, ffh, and relA were potential targets for srn225147, and the mRNAs of gtfB, gtfC, spaP, sitA, and ffh were predicted targets for srn821798, according to target prediction by IntaRNA and RNAPredator. The expression level of gtfB of one isolate in the ECC-C group was defined as 1.0. * represents $p$ value $<0.05$ and $* \star$ represents $p$ value $<0.01$ 